\title{
Effect of exercise intensity and mode on acute appetite control in men and women
}

\author{
Valéria Leme Gonçalves Panissa, Ursula Ferreira Julio, Felipe Hardt, Carolina Kurashima, \\ Fábio Santos Lira, Monica Yuri Takito, and Emerson Franchini
}

\begin{abstract}
The aim of this study was to compare the effects of exercise intensity on appetite control: relative energy intake (energy intake minus the energy expenditure of exercise; REI), hunger scores, and appetite-regulating hormones in men and women. Eleven men and 9 women were submitted to 4 experimental sessions: high-intensity intermittent all-out exercise (HIIE-A) for $60 \times 8 \mathrm{~s}$ interspersed by $12 \mathrm{~s}$ of passive recovery; high-intensity intermittent exercise (HIIE) at $100 \%$ of maximal load attained in incremental test; steady-state exercise at $60 \%$ of maximal load, matched by work done; and a control session. Exercise was performed $1.5 \mathrm{~h}$ after a standardized breakfast, and an ad libitum lunch was offered $4 \mathrm{~h}$ after breakfast. Blood concentration of insulin, cortisol, acylated ghrelin, peptideYY ${ }_{3-36}$, glucose, and hunger scores were measured when fasting, and at 1.5, 2, 3.25, and $4 \mathrm{~h}$ of experiment. REI was lower in all exercises than in the control, without differences between exercises and sex showing no compensation in energy intake because of any exercise; the hunger scores were lower only in the exercises performed at higher intensity (HIIE and HIIE-A) compared with the control. The area under the curve of acylated ghrelin was lower in the HIIE-A when compared with the control. PeptideYY ${ }_{3-36}$ was higher in men than women and cortisol higher in women than men independently of the condition. Although high-intensity exercises promoted a little more pronounced effects in the direction of suppressing the appetite, no differences were observed in REI, demonstrating that these modifications were not sufficient to affect energy intake.
\end{abstract}

Key words: sex, energy intake, appetite-regulating hormones, hunger, high-intensity intermittent exercise.

Résumé : Cette étude a pour objectif de comparer les effets de l'intensité de l'exercice sur le contrôle de l'appétit : apport énergétique relatif ("REI », apport énergétique moins dépense énergétique à l'effort), sensation de faim, hormones de l'appétit chez des femmes et des hommes. Neuf femmes et onze hommes participent à quatre séances expérimentales : exercice par intermittence d'intensité élevée à fond de train (" HIIE-A »), soit $60 \times 8 \mathrm{~s}$ incluant $12 \mathrm{~s}$ de récupération passive; exercice par intermittence d'intensité élevée ( $\mathrm{HIIE}$ ») à 100 \% de la charge maximale atteinte au cours d'un test progressif; exercice en régime stable à 60 \% de la charge maximale et apparié en fonction du travail effectué; séance de contrôle. Les sujets effectuent l'exercice $1,5 \mathrm{~h}$ après un petit déjeuner normalisé et prennent un repas ad libitum $4 \mathrm{~h}$ après le petit déjeuner. On mesure les concentrations sanguines d'insuline, de cortisol, de ghréline acylée, de peptide $\mathrm{YY}_{3-36}$, de glucose ainsi que la sensation de faim à jeun et 1,5, 2 , 3,25 et $4 \mathrm{~h}$ suivant le début de l'expérimentation. REI est plus faible dans toutes les séances d'exercice comparativement à la séance de contrôle, sans différence entre les exercices; le sexe n'est pas une variable de compensation de l'apport énergétique dans toutes les séances d'exercice; la sensation de faim est plus faible seulement dans les séances d'exercice d'intensité élevée (HIIE et HIIE-A) par rapport à la séance de contrôle. La surface sous la courbe de la ghréline acylée est plus petite dans la condition HIIE-A comparativement à la séance de contrôle. La concentration de peptide $\mathrm{YY}_{3-36}$ est plus élevée chez les hommes que chez les femmes et la concentration de cortisol est plus élevée chez les femmes que chez les hommes indépendamment de la condition. Même si les exercices d'intensité élevée favorisent une diminution un peu plus prononcée de l'appétit, on n'observe pas de différence de REI, ce qui signifie que cette diminution ne suffit pas à modifier l'apport énergétique. [Traduit par la Rédaction]

Mots-clés : sexe, apport énergétique, hormones de l'appétit, faim, exercice intermittent d'intensité élevée.

\section{Introduction}

Exercise-induced energy deficit can be achieved through different types of exercise (Thorogood et al. 2011). Typically, moderateintensity, continuous aerobic exercise is recommended to people seeking to maintain or reduce their body mass (Garber et al. 2011). However, high-intensity intermittent exercise has recently gained popularity because of its benefits relating to improved physical fitness (Helgerud et al. 2007) and body composition (Trapp et al. 2008; Panissa et al. 2016), in addition to which it can also be executed in a short period of time (Gillen and Gibala 2014).

In 2008, Trapp et al. (2008) showed that a 15-week high-intensity all-out intermittent cycling exercise $(60 \times 8$-s cycling sprints, 12 -s intervals) training program was more effective at reducing body and fat masses (total and abdominal) than moderate-intensity con-

Received 22 March 2016. Accepted 25 June 2016.

V.L.G. Panissa, U.F. Julio, F. Hardt, and E. Franchini. Department of Sport, School of Physical Education and Sport, University of São Paulo, São Paulo, Brazil.

C. Kurashima and M.Y. Takito. Department of Human Movement Pedagogy, School of Physical Education and Sport, University of São Paulo, São Paulo, Brazil.

F.S. Lira. Exercise and Immunometabolism Research Group, Department of Physical Education, Paulista State University, UNESP, Presidente Prudente, São Paulo, Brazil.

Corresponding author: Valéria Leme Gonçalves Panissa (email: valeriapanissa@gmail.com).

Copyright remains with the author(s) or their institution(s). Permission for reuse (free in most cases) can be obtained from RightsLink. 
tinuous exercise ( $60 \%$ of maximal oxygen uptake $\left.\left(\dot{V}_{2 \text { max }}\right)\right)$, equalized in total caloric expenditure. The authors suggested the postexercise acute appetite suppression as a possible mechanism underlying the high-intensity intermittent exercise (HIIE), inducing greater energy deficits and, consequently, greater fat loss than moderate-intensity exercise. However, the evidence supporting this is not consistent (Deighton et al. 2013a, 2013b).

Control of appetite and energy intake is a complex phenomenon responsive to psychological, cultural, hormonal, and neural factors. At the physiological level, appetite-regulating gut hormones play a role as episodic mediators of hunger and satiation (Woods 2009). $\mathrm{PYY}_{3-36}$ is a principal anorexigenic peptide, synthesized and released from L-cells in the distal gastrointestinal tract (Neary and Batterham 2009). Complementary to this, acylated ghrelin is an orexigenic gut peptide produced in the stomach (Patterson et al. 2011). While it is known that acute energy deficit imposed by food restriction causes an increase in food intake, this compensation does not occur when energy deficits are generated by exercise (King et al. 2011). Actually, it is well-documented that exercise decreases orexigenic peptide (acylated ghrelin) and increases anorexigenic peptides (i.e., PYY $_{3-36}$ ) (Schubert et al. 2014). In addition, exercise can influence other hormones related to appetite, such as cortisol and insulin (Begg and Woods 2013).

Although the hypothesis raised by Trapp et al. (2008) that HIIE could have more effects on acute appetite suppression when compared with moderate-intensity continuous exercise, few studies have conducted this comparison and the results are inconsistent. (Deighton et al. 2013a, 2013b; Sim et al. 2014; Martins et al. 2015).

The limitations in interpretation may be due to the lack of standardization of protocols concerning physiological responses (e.g., oxygen uptake $\left(\dot{V} \mathrm{O}_{2}\right)$ and heart rate) or mechanical parameters (e.g., speed, power output) (Deighton et al. 2013a), the lack of measurement of energy expenditure of exercise (Sim et al. 2014), or energy expenditure estimated without measuring the $\mathrm{VO}_{2}$ throughout the exercise (Deighton et al. 2013b; Martins et al. 2015), especially during HIIE when $\dot{V O}_{2}$ demonstrates a kinetic variable that can be influenced by many factors; among these duration and intensity of pause (Buchheit and Laursen 2013). Furthermore, estimate of energy expenditure is an important variable that should be calculated to reach the best value possible, given that relative energy intake is dependent on this value, since the relative energy intake is the absolute energy intake minus the energy expenditure.

Considering the possibility of sex-related differences in appetite, given that greater levels of acylated ghrelin and energy intake and lower of levels insulin may occur in women in response to short-term exercise, as opposed to men (Ebrahimi et al. 2013; Hagobian et al. 2009), there are no studies involving the effects of exercise intensity that compare men and women.

Thus, knowledge of the influence of intensity on postexercise appetite is important for individuals engaged in physical activity programs aimed at obtaining or maintaining an energetic deficit and consequently the control and reduction of body mass. Accordingly, this study aimed to investigate the effects of HIIE performed in an all-out mode $(60 \times 8$-s cycling sprints, 12 -s intervals; similar to the protocol used by Trapp et al. (2008)), fixed-intensity HIIE (100\% maximal aerobic power, MAP) and moderate continuous exercise on energy intake, hunger scores, and hormone responses (acylated ghrelin, $\mathrm{PYY}_{3-36}$, cortisol, and insulin) in men and women. The main hypotheses of the present study were that the more intense exercises would result in more pronounced alterations in the direction of suppressing appetite and energy intake and that women would present an exacerbated response in terms of compensation for the energy expenditure from exercise, compared with men.

\section{Materials and methods}

\section{Subjects}

Eleven physically active men (age, $27 \pm 3$ years; height, $178 \pm$ $8 \mathrm{~cm}$; mass, $78.0 \pm 7.8 \mathrm{~kg}$; body fat, $14.5 \% \pm 2.7 \%$; peak oxygen uptake $\left(\dot{V} \mathrm{O}_{2 \text { peak }}\right), 43.6 \pm 4.6 \mathrm{~mL} \cdot \mathrm{kg}^{-1} \cdot \mathrm{min}^{-1}$; MAP, $\left.285 \pm 50 \mathrm{~W}\right)$ and 9 women (age, $27 \pm 3$ years; height, $164 \pm 8 \mathrm{~cm}$; height, $61.8 \pm 7.6 \mathrm{~kg}$; body fat, $20.9 \% \pm 3.7 \%$; $\mathrm{VO}_{2 \text { peak }}, 36.2 \pm 4.6 \mathrm{~mL} \cdot \mathrm{kg}^{-1} \cdot \mathrm{min}^{-1}$; MAP, $187 \pm 22 \mathrm{~W}$ ) subjects participated in this study. The subjects were recruited from university and fitness centers after an advertisement of this investigation with flyers. Specific physical activities of the participants included strength training, recreational sports, cycling, or running (2-3 times per week). Participants were included if they did not report any health problems and/or neuromuscular disorders that could affect their ability to complete the study protocol. Furthermore, all were free of any drug or ingestion of nutritional supplements during the period of the study and had stable body mass 6 months before study $( \pm 5 \%$ of body mass).

Using the effect size of the present study, and an $\alpha$ value of 5\%, a sample size of the present study has a $90 \%$ power of detecting a difference between conditions and sex in relative energy intake (this variable was considered the main dependent variable to calculate power analysis). All procedures were approved by the School of Physical Education and Sport, University of São Paulo. Participants took part voluntarily in the study after being informed about the procedures, risks, and benefits and signed an informed consent form. The women were tested in the follicular phase (1 - 10 days after the onset of menstruation) of the menstrual cycle; 6 women were on oral contraceptive regimens. The follicular phase was checked by measuring the luteinizing hormone, and there was no differences between conditions $\left(F_{[3,31]}=\right.$ 0.57; $p=0.558 ; \eta^{2}=0.367$; control: $4.0 \pm 2.5$, steady-state exercise (SSE): $3.6 \pm 2.0$; HIIE: $5.0 \pm 2.5$; high-intensity intermittent all-out exercise (HIIE-A): $4.2 \pm 1.8$ ).

\section{Study design}

Subjects completed 6 sessions ( 2 screening and 4 experimental) separated by at least $72 \mathrm{~h}$ and a maximum of 1 week for men. For women this interval was longer to allow the testing to be conducted in the same phase of the menstrual cycle (they did 2 or 3 sessions per month). During the first session, anthropometric and $\dot{V} \mathrm{O}_{2 \max }$ and MAP (maximal intensity attained) test measurements on a cycle ergometer were taken. In the second session, the participants were submitted to an HIIE-A $(60 \times 8$-s cycling sprints, 12 -s intervals) to determine the total work performed (kJ). This value (kJ) was used to equalize the subsequent exercise sessions. After this exercise the participants were familiarized with the buffet, in which participants could feed ad libitum. The 4 experimental sessions were applied in randomized order using a random draw of numbers: (i) a control session in which participants did not perform any kind of exercise; (ii) an SSE (60\% of MAP); (iii) an HIIE-A (maximum effort); and (iv) an HIIE (100\% of MAP). All conditions were followed by an ad libitum meal.

Although an all-out protocols has been considered to be an efficient protocol to improve aerobic fitness and to reduce fat mass (Trapp et al. 2008), this kind of exercise has particularities that can make difficult its practical execution, because it is necessary to utilize specialized equipment, such as a mechanical cycle ergometer or treadmill, or to be performed outside. However, an alternative protocol that has also shown positive results is the use of fixed-intensity exercise based in maximum indexes (i.e., $\dot{\mathrm{VO}}_{2 \max }$ or maximum load attained in incremental test) (Gillen and Gibala 2014; Helgerud et al. 2007), but the comparison between protocols has not been explored. In this way, we added an HIIE using fixed intensity to compare the 2 main forms of prescribing high-intensity exercise. 


\section{Anthropometric measurements}

Height was measured using a stadiometer with a metric scale affixed to the floor, and body mass were measured using an electronic body-weight scale (precision $0.01 \mathrm{~kg}$ ). Body fat percentage was estimated via skinfold, circumferences, and bone diameter measurement (Drinkwater and Ross 1980). Skinfold thickness measurements were carried out using a Harpender plicometer (John Bull British Indicators, England), 3 times at each point in a rotation system (the median value was used), as described.

\section{$\dot{V} O_{\text {2peak }}$ test}

The participants performed an incremental test to volitional exhaustion on a cycle ergometer (Lode, Netherlands). The initial load was set at $30 \mathrm{~W}$ and it was increased by $25 \mathrm{~W} \cdot \mathrm{min}^{-1}$ for men and $15 \mathrm{~W} \cdot \mathrm{min}^{-1}$ for women. Cadence was set at $70 \mathrm{r} \cdot \mathrm{min}^{-1}$, and subjects were instructed to perform the test until they could no longer continue. The test was finished when subjects could not maintain the load for $5 \mathrm{~s}$ in the fixed cadence. Maximum effort was confirmed by one or more of the following: a respiratory exchange ratio $\geq 1.1 ; 10$ beats $\cdot \mathrm{min}^{-1}$ of predicted maximal heart rate by age was reached; a Borg scale rating of $\geq 19$ was reported by the participants (Borg 1982). Strong verbal encouragement was given during the test. $\dot{V O}_{2}$ was measured (MetaMax 3B, Cortex, Germany) throughout the test and the average of the last $30 \mathrm{~s}$ was defined as $\dot{V} \mathrm{O}_{2 \text { peak. }}$. The maximal load reached in the test was defined as the MAP. When the subject was not able to finish the 1-min stage, the power was expressed according to the permanence time in the last stage, determined using the following: maximal aerobic power $=$ power of last stage completed $+[$ (time, in seconds, remaining in the last stage multiplied by $25 \mathrm{~W}) / 60 \mathrm{~s}]$.

\section{Volume equalization}

To guarantee that the results obtained were related to the type and intensity of exercise performed and not affected by the differences in exercise volume, total work performed was equalized between the different exercises. In the second session the participants performed the all-out exercise used by Trapp et al. (2008), in which they cycled as fast as possible 60 times for $8 \mathrm{~s}$ interspersed by $12 \mathrm{~s}$ of passive recovery (totaling $20 \mathrm{~min}$ ). The load used was $4 \%$ (men) and $2.5 \%$ (women) of body mass. The work done in each effort was registered and the sum of all the efforts was considered the total work done $(\mathrm{kJ})$. Thus, the reference volume done was used to equalize other sessions.

\section{Experimental protocol}

Each experimental protocol started upon the arrival of the participant at approximately $0800 \mathrm{~h}$, and with the participant having fasted for at least $10 \mathrm{~h}$ previously. A cannula was inserted in an antecubital vein, then a fasting blood sample was taken (time $=$ zero/baseline). After this, participants received a standardized breakfast and serial blood samples were taken at regular intervals for a period of $4 \mathrm{~h}(2,2.5,3.25$, and $4 \mathrm{~h})$, at the same time participants were asked to rate their subjective feeling of hunger. The exercise was performed at approximately $2-2.5 \mathrm{~h}$ of the experiment. After the 4 -h period, an ad libitum buffet was offered. In all rest intervals between collections, participants remained in the laboratory and could bathe, read, or use the computer.

\section{Exercise protocols}

In all exercise sessions participants performed a warm-up at $50 \%$ MAP for 5 minutes, and after a 2-min interval they started the exercise. $\dot{\mathrm{VO}}_{2}$ was measured during the whole exercise as was lactate concentration to estimate the energy expenditure; moreover, the heart rate was also registered during the whole exercise. The $\mathrm{VO}_{2}$ and heart rate were presented by the mean of whole exercise and for its maximum indexes $\left(\% \mathrm{VO}_{2 \text { peak }}\right.$ and maximal heart rate).
HIIE-A was the same used in the reference (control) session. To ensure that the same reference volume in an all-out exercise was performed, the total work was recorded. There were no differences relating to total work performed between the reference sessions and the experimental sessions for women $(p=0.465$; intra-class correlation coefficient $=0.969$ and limits of agreement between -9 to $7 \mathrm{~kJ}$ ), or men ( $p=0.572$; intra-class correlation 0.952 and limits of agreement between -11 to $12 \mathrm{~kJ}$ ) (Bland and Altman 1986). The time spent on all protocol exercises was $20 \pm 0 \mathrm{~min}$ (8 $\mathrm{min}$ of effort and $12 \mathrm{~min}$ of pause).

HIIE consisted of 1-min repetitions at $\operatorname{MAP}\left(70 \mathrm{r} \cdot \mathrm{min}^{-1}\right)$ separated by 1-min of passive recovery on a cycle ergometer until the completion of the previously determined exercise. The time spent on the exercise protocol was $17 \pm 2 \mathrm{~min}(9 \mathrm{~min}$ of effort and $8 \mathrm{~min}$ of pause).

SSE consisted of cycling at $60 \%$ MAP $\left(70 \mathrm{r} \cdot \mathrm{min}^{-1}\right)$ until the completion of the previously determined exercise. The time spent on the exercise protocol was $19 \pm 2 \mathrm{~min}$.

\section{Standardized breakfast and ad libitum buffet meals}

In the first experimental session, the subjects were instructed to maintain their nutritional and hydration routines. Also, the subjects were asked to record what they ate all day (prior to the first experimental condition) in a food diary and further asked to maintain the same food in other conditions. The energy intake of the breakfast was fixed at $25 \%$ of the estimated daily energy needs for each participant on a sedentary day (Mifflin et al. 1990). This meal was composed of cheese, toast, and strawberry yogurt (52\% carbohydrate, $36 \%$ fat, and $13 \%$ protein).

In all experimental sessions, the participants could eat from a cold buffet comprising various food types (cheese, ham, white bread, whole-grain bread, toast, tomato, lettuce, carrots, tuna pâté, chips, orange and grape juice, soft drinks with and without sugar, chocolate bars, chocolate yogurt, and apples). The buffet was presented identically in all situations (the location of the food on the table and amounts), which the participants ate in isolation and ad libitum. All food was weighed (Toledo, modelPrix 3, Mettler-Toledo, Inc., de Columbus, Ohio, USA) and the consumption registered to calculate the energy intake. The evaluation of energy intake was conducted using Creative Nutri 4.0 (Skopein Sistemas, Brazil). To verify the energy intake and to compare all experimental conditions, the absolute (only energy intake) and relative (energy intake minus energy expenditure in exercise) values were calculated. Type of macronutrient intake was also calculated. One man was excluded from the analyses of energy intake because he presented an outlier behavior (he ate 4 times more than the mean of the men group in all conditions).

\section{Subjective hunger scores}

The hunger perception was evaluated through a validated visual analogic scale (Flint et al. 2000) of $10 \mathrm{~cm}$ in length with words anchored at each end, expressing the higher $(10 \mathrm{~cm})$ and the lower $(0 \mathrm{~cm})$ rating of hunger. Participants were instructed to make a mark on the scale representing their feeling at the moment.

\section{Exercise energy expenditure}

To estimate the energy expenditure of all exercises the sum of the contribution of the 3 energy systems (phosphagen, glycolytic, and oxidative energy systems) was used (di Prampero and Ferretti 1999). Estimates of oxidative, glycolitic, and phosphagen system use were carried out through the measurement of $\mathrm{VO}_{2}$ during activity, peak blood lactate concentration, and the fast phase of excess $\dot{V} \mathrm{O}_{2}$ after exercise, respectively. Oxidative energy system was estimated by subtracting $\dot{V} \mathrm{O}_{2}$ of rest from $\dot{V} \mathrm{O}_{2}$ during the exercise by the trapezoidal method (a method used to calculate the area under the curve (AUC) to estimate the integral). The phosphagen system contribution was estimated considering the $\mathrm{VO}_{2}$ during the fast phase of excess $\dot{V O}_{2}$ after exercise (Beneke et al. 
2004). In the present study, we fitted the kinetics of postexercise $\dot{V} \mathrm{O}_{2}$ to bi- and mono-exponential models and observed that the slow component of the bi-exponential model was negligible. Thus, the postexercise breath-by-breath $\dot{V O}_{2}$ data were fitted to a mono-exponential model and was obtained by calculating the integral of the exponential part (Origin 6.0, Microcal, Mass., USA). The participation of the glycolitic system was calculated using delta of lactate (peak lactate concentration after the exercise, minus the lactate concentration at rest), assuming that the accumulation of $1 \mathrm{mmol} \mathrm{L}^{-1}$ blood lactate concentration is equivalent to $3 \mathrm{mLO}_{2} \cdot \mathrm{kg}^{-1}$ of body mass (di Prampero and Ferretti 1999). The caloric quotient of $20.92 \mathrm{~kJ}$ (Gastin 2001) was used in all 3 different energy systems.

\section{Blood analyses}

The blood samples $(15 \mathrm{~mL})$ were immediately allocated into two $5 \mathrm{~mL}$ vacutainer tubes (Becton Dickinson, BD, São Paulo, Brazil) containing ethylenediaminetetraacetic acid for plasma separation and into one 5-mL dry vacutainer tube for serum separation. The tubes were centrifuged at $2500 \mathrm{~g}$ for $12 \mathrm{~min}$ at $4{ }^{\circ} \mathrm{C}$, and plasma and serum samples were stored at $-80^{\circ} \mathrm{C}$ until analysis. To eliminate inter-assay variance, all samples were analyzed in identical runs, resulting in an intra-assay variance of $<7 \%$. Glucose was assessed through commercial enzymatic kits (Labtest, Lagoa Santa, Brazil). Serum cortisol and acylated ghrelin were assessed using EIA commercial kits (Cayman Chemical, Ann Arbor, Mich., USA). Serum PYY (3-36) was quantified using RIA commercial kits (Phoenix Pharmaceuticals, Calif., USA). A woman presented problems with cannulisation and her blood analyses were excluded.

\section{Statistical analysis}

The data was analyzed using the Statistical Package for Social Sciences 18.0 (SPSS Inc., Chicago, Ill., USA) and presented as mean and standard deviations. For all measured variables, the estimated sphericity was verified according to Mauchly's $W$ test, and the Greenhouse-Geisser correction was used when necessary. The subjects' characteristics and work done in all-out exercise were compared through unpaired Student's $t$ tests. The comparison of the energy expenditure, $\dot{V} \mathrm{O}_{2}$, heart rate in the exercise protocols, and absolute and relative energy intake in the different conditions was conducted through a 2-way ANOVA (sex and condition) with repeated measurements in the second factor. The comparison of the macronutrient intake in the different conditions was conducted through 3-way ANOVA (sex, condition, and type of macronutrient) with repeated measurements of the second and third factors. The hunger scores and blood variables in the different conditions were compared through a 3-way ANOVA (sex, condition, and time) with repeated measurements of the second and third factors. In addition, the AUC was calculated for blood variables and hunger (AUC ${ }_{\text {hunger }}$ ) scores using the trapezoidal method and through a 2-way ANOVA (sex and condition) with repeated measurements of the second factor was used. When a significant difference was observed, a Bonferroni post hoc test was applied. The correlation between variables was verified through Pearson correlation coefficient. The effect size (eta-squared; $\eta^{2}$ ) of each test was calculated for all analyses. Statistical significance was set at $p<0.05$.

\section{Results}

\section{Exercise responses}

For the total work done $\left(t=-6.82 ; p<0.001 ; \eta^{2}=0.739\right)$, the men presented higher total work done $(145.6 \pm 25.5 \mathrm{~kJ})$ than did the women $(82.0 \pm 12.3 \mathrm{~kJ})$.

For \%VO ${ }_{2 \text { peak }}$ during exercises (Table 1 ) there was a main effect for condition $\left(F_{[2,36]}=10.06 ; p<0.001 ; \eta^{2}=0.358\right)$, with higher $\% \dot{V} \mathrm{O}_{2 \text { peak }}$ in HIIE-A than HIIE $(p<0.001)$ and SSE $(p=0.003)$ exercises.
Table 1. Oxygen uptake in percentage to peak values in high-intensity intermittent all-out exercise (HIIE-A), highintensity intermittent exercise (HIIE), and steady-state exercise (SSE) conditions in men and women.

\begin{tabular}{llll}
\hline & Men $(n=11)$ & Women $(n=9)$ & All $(n=20)$ \\
\hline${\text { Mean \%V } \mathrm{O}_{\text {2peak }}}$ & & & \\
HIIE-A $^{*}$ & $73.5 \pm 6.9$ & $74.8 \pm 13.3$ & $74.1 \pm 10.0$ \\
HIIE & $64.7 \pm 5.9$ & $64.4 \pm 3.9$ & $66.0 \pm 8.8$ \\
SSE & $68.4 \pm 8.1$ & $63.2 \pm 9.3$ & $64.6 \pm 5.0$ \\
Mean \%HR & & & \\
HIIE-A $_{\text {max }}$ & & & \\
HIIE & $89.0 \pm 4.7$ & $87.4 \pm 4.6$ & $88.3 \pm 4.6$ \\
SSE & $83.7 \pm 6.1$ & $84.3 \pm 6.2$ & $84.0 \pm 6.0$ \\
\hline
\end{tabular}

Note: Values are means and standard deviation. \% $\mathrm{HR}_{\max }$, percentage of maximal heart rate; $\% \mathrm{VO}_{2 \text { peak }}$, percentage of peak oxygen uptake.

${ }^{*}$ Different from HIIE and SSE $(p<0.05)$.

For maximal heart rate percentage during exercises (Table 1), there was a main effect for condition $\left(F_{[2,36]}=10.89 ; p<0.001 ; \eta^{2}=\right.$ $0.377)$, with higher maximal heart rate percentage in HIIE-A than HIIE $(p=0.012)$ and SSE $(p<0.001)$ exercises.

For energy expenditure during exercises (Table 2), there was a main effect for condition $\left(F_{[2,36]}=14.75 ; p<0.001 ; \eta^{2}=0.450\right)$, with higher energy expenditure in HIIE-A than HIIE and SSE exercises ( $p<0.001$ for both comparisons). There was also a main effect for $\operatorname{sex}\left(F_{[1,18]}=52.76 ; p<0.001 ; \eta^{2}=0.745\right)$, with higher energy expenditure in men than in women $(p<0.001)$.

\section{Ad libitum energy intake and macronutrient composition}

For absolute energy intake (Table 3), there was a main effect for $\operatorname{sex}\left(F_{[1,17]}=6.29 ; p=0.022 ; \eta^{2}=0.270\right)$, with higher absolute energy intake in men than in women $(p=0.022)$. For the relative energy intake (Table 3$)$, there was a main effect for condition $\left(\mathrm{F}_{[3,45]}=\right.$ 11.96; $\left.p<0.001 ; \eta^{2}=0.413\right)$, with higher relative energy intakes in the control than in the HIIE-A, HIIE, and SSE conditions $(p<0.001$ for all comparisons).

For macronutrient intake (data not shown), there was a main effect of type of macronutrient intake $\left(\mathrm{F}_{[1.2,19.9]}=136.1 ; p<0.001\right.$; $\eta^{2}=0.889$ ), with lower protein intake than carbohydrate and fat ( $p<0.001$ for both comparisons), and higher carbohydrate intake than fat $(p<0.001)$.

\section{Subjective ratings of hunger}

For subjective hunger ratings (Fig. 1) there was a main effect for condition $\left(F_{[2.3,42.0]}=4.74 ; p=0.010 ; \eta^{2}=0.208\right)$, with lower subjective hunger ratings in HIIE $(p=0.034)$ and HIIE-A $(p=0.043)$ than the control condition. There was also an effect of time $\left(F_{[2.0,39.7]}=\right.$ 76.65; $p<0.001 ; \eta^{2}=0.809$ ), increasing over time, with lower subjective hunger ratings at $2 \mathrm{~h}$ than at $3.15 \mathrm{~h}$ and $4 \mathrm{~h}(p<0.001$ for both comparisons), lower at $2.5 \mathrm{~h}$ than at $3.25 \mathrm{~h}$ and $4 \mathrm{~h}(p<0.001$ for both comparisons), and lower at $3.25 \mathrm{~h}$ than at $4 \mathrm{~h}(p<0.001)$. For $\mathrm{AUC}_{\text {hunger }}$ ratings there was a main effect of condition $\left(F_{[2.0,36.5]}=4.30 ; p=0.020 ; \eta^{2}=0.228\right)$, with lower values in HIIE $\left(p=0.023 ; 484.1 \pm 197.5 \mathrm{~cm} \cdot \mathrm{min}^{-1}\right)$, and HIIE-A $(p=0.038 ; 505.3 \pm$ $\left.229.8 \mathrm{~cm} \cdot \mathrm{min}^{-1}\right)$ than in the control condition $\left(672.3 \pm 248.6 \mathrm{~cm} \cdot \mathrm{min}^{-1}\right)$.

\section{Hormones and glucose}

For acylated ghrelin (Fig. 2) there was just a main effect of time $\left(F_{[4,68]}=24.3 ; p<0.001 ; \eta^{2}=0.588\right)$, with higher values in the baseline state than at $2 \mathrm{~h}, 2.5 \mathrm{~h}$, and $3.25 \mathrm{~h}(p<0.001$ for all comparisons), lower at $2 \mathrm{~h}$ than at $4 \mathrm{~h}(p<0.001)$, and lower at $2.5 \mathrm{~h}$ than $3.25 \mathrm{~h}(p=0.034)$ and $4 \mathrm{~h}(p<0.001)$. For ghrelin AUC $\left(\mathrm{AUC}_{\text {ghrelin }}\right)$ there was a main effect of condition $\left(F_{[1,59] ;}=27.0 ; p=0.020 ; \eta^{2}=\right.$ $0.182)$, with lower values in HIIE-A $\left(80.9 \pm 40.3 \mathrm{ng} \cdot \mathrm{mL}^{-1} \cdot \mathrm{min}^{-1}\right)$ than in the control condition ( $\left.p=0.029 ; 109.2 \pm 57.0 \mathrm{ng} \cdot \mathrm{mL}^{-1} \cdot \mathrm{min}^{-1}\right)$.

For $\mathrm{PYY}_{3-36}$ (Fig. 2) there was just a main effect of $\operatorname{sex}\left(F_{[1,16]}=8.55\right.$; $\left.p=0.009 ; \eta^{2}=0.348\right)$, with higher values in men than women $(p=0.009)$. 
Table 2. Energy expenditure (kJ) during high-intensity intermittent all-out exercise (HIIE-A), high-intensity intermittent exercise (HIIE), and steady-state exercise (SSE) in men and women.

\begin{tabular}{llll}
\hline & \multicolumn{3}{l}{ Total energy expenditure $(\mathrm{kJ})$} \\
\cline { 2 - 4 } & Men $(n=11)^{*}$ & Women $(n=9)$ & All $(n=20)$ \\
\hline HIIE-A $^{\dagger}$ & $945 \pm 208$ & $650 \pm 165$ & $805 \pm 238$ \\
HIIE & $815 \pm 149$ & $469 \pm 56$ & $651 \pm 209$ \\
SSE & $862 \pm 127$ & $470 \pm 57$ & $676 \pm 224$ \\
\hline
\end{tabular}

Note: Values are means and standard deviation.

${ }^{*}$ Men different from women $(p<0.001)$.

†Different from HIIE and SSE $(p<0.05)$.

Table 3. Absolute and relative energy intake (kJ) in high-intensity intermittent all-out exercise (HIIE-A), high-intensity intermittent exercise (HIIE), steady-state exercise (SSE), and control conditions in men and women.

\begin{tabular}{lclc}
\hline & Men $(n=10)^{*}$ & Women $(n=9)$ & All $(n=19)$ \\
\hline Absolute energy intake (kJ) & & & \\
$\quad$ HIIE-A & $5155 \pm 1642$ & $3432 \pm 1016$ & $4339 \pm 1608$ \\
HIIE & $4582 \pm 1850$ & $3593 \pm 935$ & $4113 \pm 1535$ \\
SSE & $4948 \pm 1621$ & $3109 \pm 986$ & $4077 \pm 1624$ \\
$\quad$ Control & $4913 \pm 1826$ & $3221 \pm 770$ & $4111 \pm 1638$ \\
Relative energy intake (kJ) & & & \\
HIIE-A & $4210 \pm 1747$ & $2782 \pm 1041$ & $3533 \pm 1595$ \\
HIIE & $3767 \pm 1902$ & $3126 \pm 926$ & $3463 \pm 1516$ \\
SSE & $4087 \pm 1679$ & $2636 \pm 999$ & $3400 \pm 1551$ \\
Control & $4913 \pm 1826$ & $3221 \pm 770$ & $4111 \pm 1638$ \\
\hline
\end{tabular}

Note: Values are means and standard deviation. Relative energy intake is absolute energy intake minus energy expenditure from exercise.

${ }^{*}$ Different from women $(p<0.05)$.

†Different from HIIE-A, HHIE, and SSE $(p<0.05)$.

For $\mathrm{AUC}_{\text {pyy3-36 }}$ there was also a sex effect $\left(F_{[1,16]}=6.18 ; p=0.024 ; \eta^{2}=\right.$ $0.270)$, with higher values in men $\left(27970.2 \pm 1636.0 \mathrm{pg} \cdot \mathrm{mL}^{-1} \cdot \mathrm{min}^{-1}\right)$ than women $\left(p=0.024 ; 25612.6 \pm 2832.1 \mathrm{pg} \cdot \mathrm{mL}^{-1} \cdot \mathrm{min}^{-1}\right)$.

For glucose (Fig. 3$)$ there was just a main effect of time $\left(F_{[2.4,41.3]}=\right.$ 8.63; $\left.p<0.001 ; \eta^{2}=0.336\right)$, with lower values in the baseline state than at $2.5 \mathrm{~h}(p<0.001)$, and lower at $2 \mathrm{~h}$ than at 2.5 and $3.25 \mathrm{~h}$ ( $p<0.001$ for both comparisons). There were no differences for glucose AUC.

For insulin (Fig. 3) there was a main effect of time $\left(F_{[2,55] ;}=22.44\right.$; $\left.p<0.001 ; \eta^{2}=0.569\right)$, with lower values when baseline than at $2 \mathrm{~h}$ $(p<0.001)$ and $3.25 \mathrm{~h}(p=0.013)$, higher at $2 \mathrm{~h}$ than at 2.5, 3.25, and $4 \mathrm{~h}(p<0.001$ for all comparisons), higher at 2.5 than at $4 \mathrm{~h}$ $(p=0.026)$, and higher at 3.25 than $4 \mathrm{~h}(p=0.026)$. There was also an interaction between condition and time $\left(\mathrm{F}_{[4.9,84.9]}=1.98 ; p=0.027\right.$; $\left.\eta^{2}=0.104\right)$, with higher values in HIII-A than control conditions at $3.25 \mathrm{~h}(p=0.019)$, and lower values in SSE than control conditions at $2.5 \mathrm{~h}(p=0.007)$. There were no differences for $\mathrm{AUC}_{\text {insulin }}$.

For cortisol (Fig. 4) there was a sex main effect $\left(F_{[1,17]}=13.86\right.$; $p=0.001 ; \eta^{2}=0.449$ ), with lower values in men than women $(p=0.001)$, and time effects $\left(F_{[4,68]}=8.83 ; p<0.001 ; \eta^{2}=0.341\right)$, with higher values when baseline than at $2 \mathrm{~h}(p=0.001), 3.25 \mathrm{~h}$ $(p=0.001)$ and $4 \mathrm{~h}(p<0.001)$. There was also interactions between condition and time $\left(F_{[12,204]}=2.62 ; p=0.002 ; \eta^{2}=0.133\right)$ with higher values in HIIE-A than the control condition at $2.5 \mathrm{~h}(p=0.019)$. For cortisol AUC there was a main effect of $\operatorname{sex}\left(F_{[1,17]}=14.68 ; p=0.001 ; \eta^{2}=\right.$ $0.463)$ with higher values in women $\left(8499.4 \pm 4065.5 \mathrm{pg} \cdot \mathrm{mL}^{-1} \cdot \mathrm{min}^{-1}\right)$ than men $\left(p=0.001 ; 3354.3 \pm 1377.1 \mathrm{pg} \cdot \mathrm{mL}^{-1} \cdot \mathrm{min}^{-1}\right)$.

\section{Correlations}

There was a correlation between the absolute energy intake and $\mathrm{AUC}_{\text {hunger }}$ in all conditions involving exercise: HIIE-A ( $r=0.504$; $p=0.033)$; HIIE $(r=0.532 ; p=0.023)$; and SSE $(r=0.493 ; p=0.038)$. Furthermore, the same occurred with the relative energy intake and AUC hunger: $_{\text {HIE-A }}(r=0.534 ; p=0.023)$; HIIE $(r=0.601$; $p=0.008)$; and SSE $(r=0.541 ; p=0.020)$.

\section{Discussion}

The main finding of the present study was that relative energy intake was lower in the 3 exercises than the control conditions and no differences were observed in relative energy intake between the exercises or sexes. On the other hand, hunger scores were lower only in the exercises performed at higher intensity (HIIE and HIIE-A) compared with the control condition without

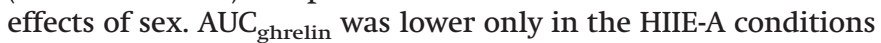
when compared with the control, showing that although hormonal and perceptive modifications for directing the suppression of appetite were more pronounced in the HIIE and HIIE-A, relative energy intake did not differ between the exercise protocols.

Although 3 types of exercise were equalized for total work done, the energy expenditure was different, with higher values in the HIIE-A than the SSE or HIIE. The higher energy expenditure in the HIIE-A can be explained by more elevated $\mathrm{VO}_{2}$ during this exercise. This occurred because the efforts were performed at high intensity and the short period of pause between efforts (12 s) did not permit a significant reduction in $\mathrm{VO}_{2}$ during the recovery periods and consequently the $\mathrm{VO}_{2}$ and energy expenditure were greater when compared with the other protocols (Christmass et al. 1999; Franchini et al. 2013). The same occurred in maximal heart rate percentage since those values were greater than not only the SSE protocols but also the HIIE.

The quantification of energy expenditure is a very important variable in studies aimed at analyzing the effects of exercise on relative energy intake. Therefore, it is extremely important that the estimate for this variable be performed using methods that consider oxygen uptake during the exercise session (mainly in $\mathrm{HIIE}$, which comprises many variations in $\dot{V}_{2}$ ). Moreover, to obtain the best estimate possible, this quantification should consider the 3 energy systems to attain a more complete estimate, particularly when more than 1 exercise protocol is involved. Schubert et al. (2013) published a meta-analysis and reported a great range in energy expenditures in this kind of study (335 to $6500 \mathrm{~kJ}$ ), showing that the studies that estimated energy expenditure may have over- or underestimated the energy expenditure during exercise, which could limit the interpretation of the outcomes.

With respect to effect of intensity, we found similar outcomes to Deighton et al. (2013b), as alterations in the direction of suppressing appetite were more pronounced in high-intensity exercises, without alterations in energy intake. These authors used energy-matched continuous ( $60 \mathrm{~min}$ at $\left.60 \% \dot{\mathrm{V}} \mathrm{O}_{2 \max }\right)$ and HIIE $(10 \times$ 4:2 min at $\left.85 \%-95 \% \dot{V O}_{2 \max }\right)$, and found that the HIIE had a pronounced effect on appetite suppression (hunger, satisfaction, fullness, and prospective food consumption). Appetite was suppressed up to the completion of exercise in the HIIE trial compared with the control trial. Moreover, plasma $\mathrm{PYY}_{3-36}$ was higher in the HIIE when considering the total trial $(8 \mathrm{~h})$ than in the control condition. Neither difference was found between the control and SSE. Unfortunately, the authors did not measure acylated ghrelin. We did not observe effects on $\mathrm{PYY}_{3-36}$, but it should be highlighted that the protocols used in the present study were 3 times lower in terms of external work, energy expenditure, and time spent.

In the present study the $\mathrm{AUC}_{\text {ghrelin }}$ was lower in the HIIE-A compared with the control, and this alteration was not observed in the SSE or HIIE. This may have occurred because of the greater intensity $\left(\% \dot{V}_{2 \text { peak }}\right)$ but as the energy expenditure in the HIIE-A was greater we cannot discard that it could have occurred because of energy expenditure, and this relation it is not well defined in the literature. Alterations in blood glucose could help to explain alterations that occur because of exercise protocol since it can act peripherally and centrally to affect appetite regulation (Begg and Woods 2013), but we did not observe this change when conditions and sex were compared. 
Fig. 1. Subjective hunger ratings (A and B for men and women, respectively) in high-intensity intermittent all-out exercise (HIIE-A), highintensity intermittent exercise (HIIE), steady-state exercise (SSE), and control conditions across time (2, 2.5, 3.25, and $4 \mathrm{~h})$ in men and women. Data are means \pm standard deviation. *, Different from HIIE-A and HIIE $(p<0.001)$; $\dagger$, different from 3.25 and $4 \mathrm{~h}(p<0.05)$; $\ddagger$, different from $4 \mathrm{~h}(p<0.05)$.
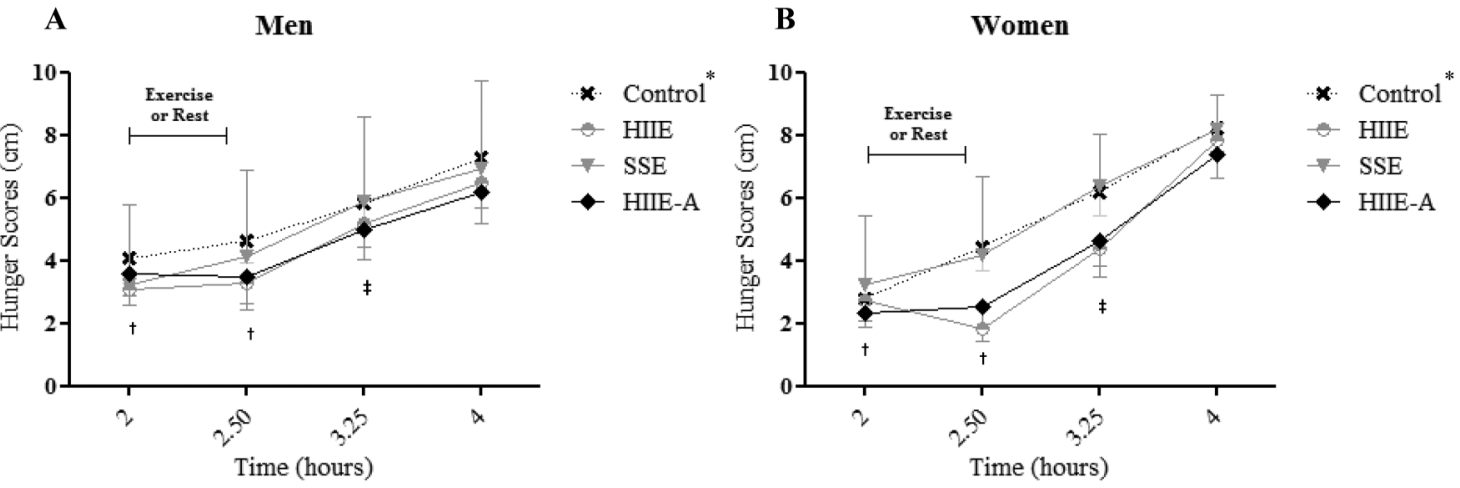

Fig. 2. Acylated ghrelin (A and B for men and women, respectively) and $\mathrm{PYY}_{3-36}$ (C and D for men and women, respectively) in high-intensity intermittent all-out exercise (HIIE-A), high-intensity intermittent exercise (HIIE), steady-state exercise (SSE), and control conditions across time $(2,2.5,3.25$, and $4 \mathrm{~h})$ in men and women. Data are means \pm standard deviation. *, Different from $2,2.5$, and $3.25 \mathrm{~h}(p<0.001)$; $\dagger$, different from $4 \mathrm{~h}(p<0.05)$; , different from 3.25 and $4 \mathrm{~h}(p<0.05)$; §, different from women $(p<0.05)$.

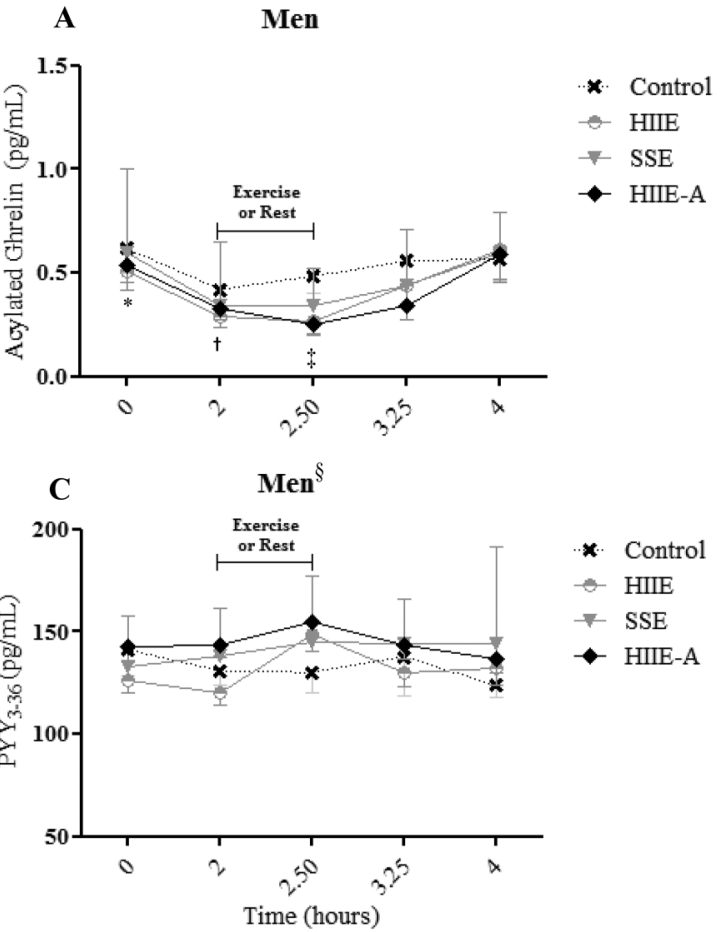

In addition, there was a pronounced cortisol at $2.5 \mathrm{~h}$ (immediately postexercise) and insulin response at $3.25 \mathrm{~h}$ (45 min postexercise) in the HIIE-A compared with the control. It is known that during exercise the hypothalamic-pituitary-adrenal (HPA) axis is stimulated mainly to mobilize energy (Hill et al. 2008). The activation of the HPA axis is needed to stimulate corticotropin-release factor (CRF) in the hypothalamus, and CRF may be a candidate for the short-term suppressive effect of exercise on energy intake (Kawaguchi et al. 2005). The higher levels of insulin $45 \mathrm{~min}$ postexercise could have occurred to restore glycogen stores (Jentjens and Jeukendrup 2003); however, it is known that this hormone is an important anorexigenic (Begg and Woods 2013). Therefore, the more pronounced elevated values for cortisol, insulin, and lower AUC of acylated ghrelin concentrations in the HIIE-A compared with the control condition demonstrated that the HIIE-A induced a more

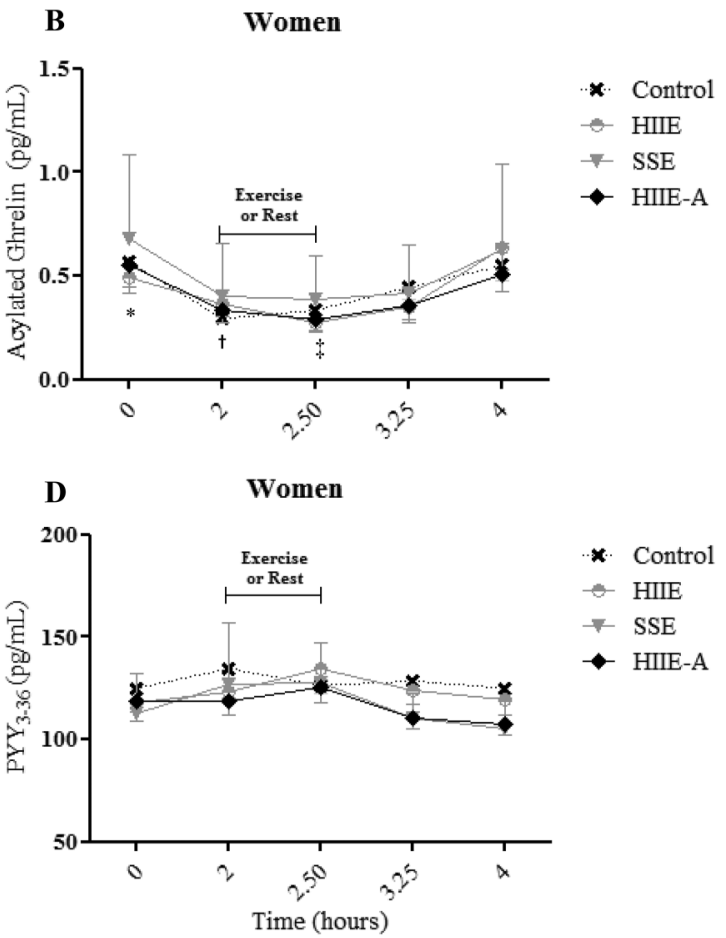

pronounced anorexigenic effect and that it occurred by different ways.

Nevertheless, despite the alterations in hunger, acylated ghrelin, insulin, and cortisol between exercises, the relative energy intake between exercises was not affected. Other studies found similar outcomes, i.e., alterations in appetite and gut hormones without alterations in energy intake (Deighton et al. 2014; Kawano et al. 2013). In the present study, alteration promoted by exercise mainly occurred immediately postexercise and the ad libitum buffet was only provided $90 \mathrm{~min}$ after the exercise. The longer time between these more pronounced alterations and the ad libitum buffet could explain the lack of differences between the exercise protocols. This justification is reinforced by a recent study that showed that relative energy intake was inferior when the exercise 
Fig. 3. Glucose (A and B for men and women, respectively) and insulin ( $C$ and D for men and women, respectively) in high-intensity intermittent all-out exercise (HIIE-A), high-intensity intermittent exercise (HIIE), steady-state exercise (SSE), and control condition, and in the different time trials $(2,2.5,3.25$ and $4 \mathrm{~h})$ for men and women. Data are means \pm standard deviation. ${ }^{*}$, Different from $2.5 \mathrm{~h}(p<0.05)$; $\dagger$, different from 2.5 and $3.25 \mathrm{~h}(p<0.05)$; $\ddagger$, different from $0,2.5,3.25$, and $4 \mathrm{~h}(p<0.05)$; §, different from 2.5 and $3.25 \mathrm{~h}(p<0.05) ; \|$, control condition different from HIIE-A at $3.25 \mathrm{~h}$ and from SSE at $2.5 \mathrm{~h}(p<0.05)$.
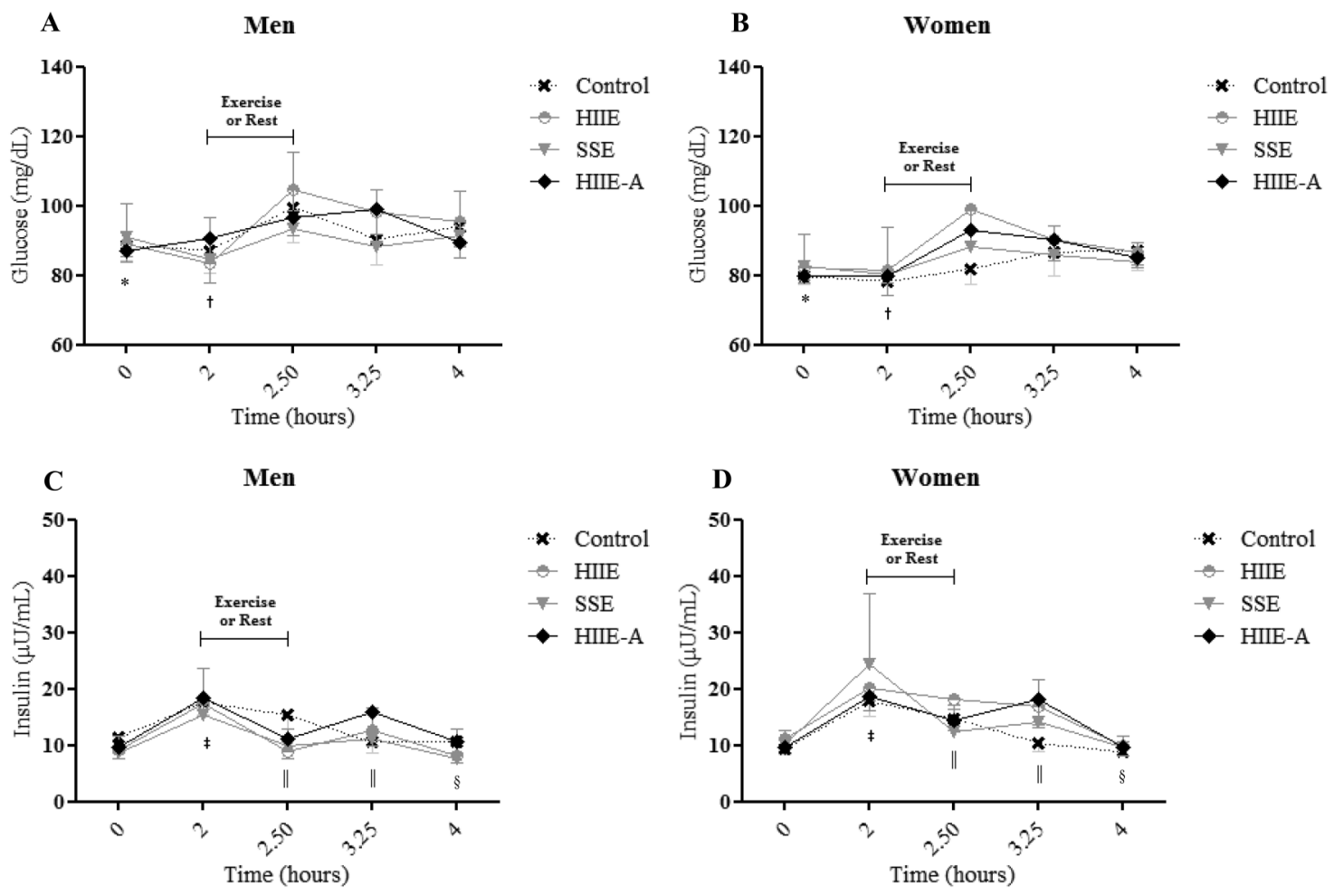

Fig. 4. Cortisol (A and B for men and women, respectively) in the high-intensity intermittent all-out exercise (HIIE-A), high-intensity intermittent exercise (HIIE), steady-state exercise (SSE), and control condition across time (2, 2.5, 3.25, and $4 \mathrm{~h}$ ) in men and women. Data are means \pm standard deviation. *, different from 2, 2.5, 3.25, and $4 \mathrm{~h}(p<0.05)$; $\dagger$, HIIE-A different from control $(p<0.05)$; $\ddagger$, different from women $(p<0.05)$.
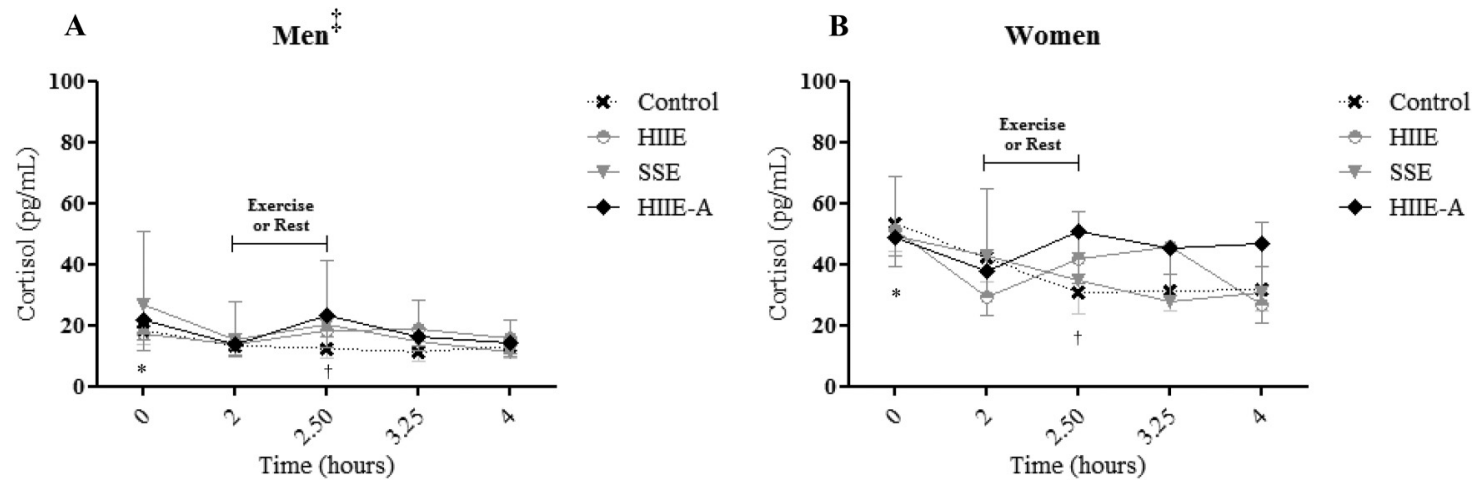

session was performed immediately prior to the meal compared with the condition after a 2-h delay (Albert et al. 2015).

However, the complex nature of appetite regulation involves other factors that are beyond the analysis of the present study, such as hedonic signals and gastric emptying that also play a role in postexercise appetite (Crabtree et al. 2014;Evero et al. 2012; Horner et al. 2015), the latter being affected by intensity (Horner et al. 2015), which can delay gastric emptying, which in turn can contribute to suppressing appetite (Janssen et al. 2011).

With respect to differences in men and women, our results corroborate with Hagobian et al. (2013) and Cadieux et al. (2014), who analyzed acute responses in men and women and found lower relative energy intake after exercise compared with the

control, regardless of sex. Therefore, our data reinforce that women do not compensate for energy expenditure in exercise any more than men, and this was also observed at different intensities, at least in this kind of population. However, in should be considered that in the present study and in the study of Hagobian et al. (2013) and Cadieux et al. (2014), the women performed the experimental sessions during the follicular phase and these results are limited to this phase of the menstrual cycle and to a specific population of physically active, eutrophic individuals.

With respect to sex differences, we observed only a main effect for PYY ${ }_{3-36}$ (women lower than men) and cortisol (women higher than men), independent of condition (exercise or control). Higher cortisol in women can be explained by the use of oral contracep- 
tives (Boisseau et al. 2013), which increases free cortisol levels. With respect to PYY, few studies have examined the effects of sex on $\mathrm{PYY}_{3-36}$ concentrations and the results are contradictory (Cahill et al. 2014; Kim et al. 2005), but further investigations should be conducted to understand the effects of these differences on postexercise appetite.

Concerning individual variability we observed that the majority of participants presented an energy deficit (16 of 19 in HIIE-A; 15 of 19 in HIIE; 17 of 19 in SSE) and the subjects that had compensatory intakes were different. Thus, we were not able to identify participants who presented a consistent increase in energy intake or any correspondence with any variable that could help to explain this behavior.

As a limitation, both women taking and not taking oral contraceptives were included in the study. It is known that the effects of the menstrual cycle on appetite and food intake do not appear to differ depending on contraceptive use (Tucci et al. 2010); therefore, we believe that this factor has a minor effect on our results. However, in relation to women, the longer time taken for data collection occurred as some women performed only 2 sessions per month and consequently prolonged the tests for 2 or 3 months to complete 6 sessions. Two participants took a shower postexercise and water immersion can influence appetite postexercise (Halse et al. 2011), although we believe that this also has a minor effect on outcomes, given that only 2 participants took a shower and a shower does not comprise water immersion.

Moreover, future studies can manipulate the time of exercise regarding proximity of buffet meal in function of intensity to verify if the modifications generated by intensity can affect energy intake, since we had a time window of $90 \mathrm{~min}$ between exercise and energy intake and it seems that the anorexigenic effect of exercise is more pronounced when exercise is done immediately before buffet meal. This experimental design could help to understand if physiological and perceptive modifications are able to modify energy intake behavior.

In conclusion, none of exercise protocols generated a compensatory increase in energy intake in men and women; the acylated ghrelin and hunger perception were more suppressed and cortisol and insulin were more elevated in the HIIE-A compared with the control, regardless of sex. Although there were little modifications in hunger scores and hormones in direction to suppress appetite promoted by high-intensity exercises, there was no differences in relative energy intake, showing that these alterations were not sufficient to interfere in energy intake. Thus, our findings reinforce the notion that the regulation of energy intake is very complex, and that appetite hormones did not have a major impact on acute energy intake in the present study.

\section{Conflicts of interest statement}

The authors declare that there are no conflicts of interest.

\section{Acknowledgements}

We thank Barbara M. M. Antunes and Loreana Silveira for their help with blood analyses, and all of the volunteers for their participation in this study. This study was supported by FAPESP (2011/ 22862-9). Ursula Ferreira Julio was supported by FAPESP (2011/ 22105-3).

\section{References}

Albert, M.H., Drapeau, V., and Mathieu, M.E. 2015. Timing of moderate-tovigorous exercise and its impact on subsequent energy intake in young males. Physiol. Behav. 151: 557-562. doi:10.1016/j.physbeh.2015.08.030. PMID: 26325014.

Begg, D.P., and Woods, S.C. 2013. The endocrinology of food intake. Nat. Rev. Endocrinol. 9: 584-597. doi:10.1038/nrendo.2013.136. PMID:23877425.

Beneke, R., Beyer, T., Jachner, C., Erasmus, J., and Hütler, M. 2004. Energetics of karate kumite. Eur. J. Appl. Physiol. 92(4-5): 518-523. PMID:15138826.

Bland, J.M., and Altman, D.G. 1986. Statistical methods for assessing agreement between two methods of clinical measurement. Lancet, 1: 307-10. PMID: 2868172.
Boisseau, N., Enea, C., Diaz, V., Dugué, B., Corcuff, J.B., and Duclos, M. 2013. Oral contraception but not menstrual cycle phase is associated with increased free cortisol concentrations and low hypothalamo-pituitary-adrenal axis reactivity. J. Endocrinol. Invest. 36(11): 955-964. PMID:23698556.

Borg, G.A. 1982. Psychophysical bases of perceived exertion. Med. Sci. Sports Exerc. 14(5): 377-381. PMID:7154893.

Buchheit, M., and Laursen, P.B. 2013. High-intensity interval training, solutions to the programming puzzle: Part I: cardiopulmonary emphasis. Sports Med. 43(5): 313-338. doi:10.1007/s40279-013-0029-x. PMID:23539308.

Cadieux, S., McNeil, J., Lapierre, M.P., Riou, M., and Doucet, É. 2014. Resistance and aerobic exercises do not affect post-exercise energy compensation in normal weight men and women. Physiol. Behav. 130: 113-119. doi:10.1016/j. physbeh.2014.03.031. PMID:24726390.

Cahill, F., Ji, Y., Wadden, D., Amini, P., Randell, E., Vasdev, S., et al. 2014. The association of serum total peptide YY (PYY) with obesity and body fat measures in the CODING study. Plos One, 9(4): e95235. doi:10.1371/journal.pone. 0095235. PMID:24743402.

Christmass, M.A., Dawson, B., and Arthur, P.G. 1999. Effect of work and recovery duration on skeletal muscle oxygenation and fuel use during sustained intermittent exercise. Eur. J. Appl. Physiol. Occup. Physiol. 80: 436-447. doi:10. 1007/s004210050615. PMID:10502077.

Crabtree, D.R., Chambers, E.S., Hardwick, R.M., and Blannin, A.K. 2014. The effects of high-intensity exercise on neural responses to images of food. Am. J. Clin. Nutr. 99(2): 258-267. doi:10.3945/ajcn.113.071381. PMID:24305681.

Deighton, K., Barry, R., Connon, C.E., and Stensel, D.J. 2013a. Appetite, gut hormone and energy intake responses to low volume sprint interval and traditional endurance exercise. Eur. J. Appl. Physiol. 113(5): 1147-1156. doi:10.1007/ s00421-012-2535-1. PMID:23111564.

Deighton, K., Karra, E., Batterham, R.L., and Stensel, D.J. 2013b. Appetite, energy intake, and PYY3-36 responses to energy-matched continuous exercise and submaximal high-intensity exercise. Appl. Physiol. Nutr. Metab. 38(9): 947952. doi:10.1139/apnm-2012-0484. PMID:23905660.

Deighton, K., Batterham, R.L., and Stensel, D.J. 2014. Appetite and gut peptide responses to exercise and calorie restriction. The effect of modest energy deficits. Appetite, 81: 52-59. PMID:24911618.

di Prampero, P.E., and Ferretti, G. 1999. The energetics of anaerobic muscle metabolism: a reappraisal of older and recent concepts. Respir. Physiol. 118(2-3): 103-115. doi:10.1016/S0034-5687(99)00083-3. PMID:10647856.

Drinkwater, D.T., and Ross, W.D. 1980. Anthropometric fractionation of body mass. In Kinanthropometry II. Edited by Ostyn, M., Beunen, G., and Simon, J. University Park Press, Baltimore, Md., USA. pp. 177-189.

Ebrahimi, M., Rahmani-Nia, F., Damirchi, A., Mirzaie, B., and Pur, S.A. 2013. Effect of short-term exercise on appetite, energy intake and energyregulating hormones. Iran J. Basic Med. Sci. 16: 829-34. PMID:23997912.

Evero, N., Hackett, L.C., Clark, R.D., Phelan, S., and Hagobian, TA. 2012. Aerobic exercise reduces neuronal responses in food reward brain regions. J. Appl. Physiol. 112(9): 1612-1619. doi:10.1152/japplphysiol.01365.2011. PMID:22383502.

Flint, A., Raben, A., Blundell, J.E., and Astrup, A. 2000. Reproducibility, power and validity of visual analogue scales in assessment of appetite sensations in single test meal studies. Int. J. Obes. Relat. Metab. Disord. 24: 38-48. doi:10. 1038/sj.ijo.0801083. PMID:10702749.

Franchini, E., Panissa, V.L.G., and Julio, U.F. 2013. Physiological and performance responses to intermittent Uchi-komi in Judo. J. Strength Cond. Res. 27(4): 1147-1155. doi:10.1519/JSC.0b013e3182606d27. PMID:22692119.

Garber, C.E., Blissmer, B., Deschenes, M.R., Franklin, B.A., Lamonte, M.J., Lee, I.M., et al.; American College of Sports Medicine. 2011. Quantity and quality of exercise for developing and maintaining cardiorespiratory, musculoskeletal, and neuromotor fitness in apparently healthy adults: guidance for prescribing exercise. Med. Sci. Sports Exerc. 43(7): 1334-1359. doi: 10.1249/MSS.0b013e318213fefb. PMID:21694556.

Gastin, P.B. 2001. Energy system interaction and relative contribution during maximal exercise. Sports Med. 31(10): 725-741. doi:10.2165/00007256-20013110000003. PMID:11547894.

Gillen, J.B., and Gibala, M.J. 2014. Is high-intensity interval training a timeefficient exercise strategy to improve health and fitness? Appl. Physiol. Nutr. Metab. 39: 409-412. doi:10.1139/apnm-2013-0187. PMID:24552392.

Hagobian, T.A., Scharoff, C.G., Stephens, B.R., Wade, G.N., Silva, J.E., Chipkin, S.R., et al. 2009. Effects of exercise on energy-regulating hormones and apetite in men and women. Am. J Physiol. Regul. Integr. Comp. Physiol. 296: R233-242. PMID:19073905.

Hagobian, T.A., Yamashiro, M., Hinkel-Lipsker, J., Streder, K., Evero, N., and Hackney, T. 2013. Effects of acute exercise on appetite hormones and ad libitum energy intake in men and women. Appl. Physiol. Nutr. Metab. 38: 66-72. doi:10.1139/apnm-2012-0104. PMID:23368830.

Halse, R.E., Wallman, K.E., and Guelfi, K.J. 2011. Postexercise water immersion increases short-term food intake in trained men. Med. Sci. Sports Exerc. 43(4): 632-638. PMID:20798665.

Helgerud, J.K., Hoyal, E., Wang, T., Karlsen, T., Berg, P., Bjerkaas, M., et al. 2007. Aerobic High-Intensity Intervals Improve VO2max More Than Moderate Training. Med. Sci. Sports Exerc. 39(4): 665-671. doi:10.1249/mss.0b013e3180304570. PMID:17414804.

Hill, E.E., Zack, E., Battaglini, C., Viru, M., Viru, A., and Hackney, A.C. 2008. 
Exercise and circulating cortisol levels: the intensity threshold effect. J. Endocrinol. Invest. 31(7): 587-591. doi:10.1007/BF03345606. PMID:18787373.

Horner, K.M., Schubert, M.M., Desbrow, B., Byrne, N.M., and King, N.A. 2015. Acute exercise and gastric emptying: A meta-analysis and implications for appetite control. Sports Med. 45(5): 659-678. doi:10.1007/s40279-014-0285-4. PMID:25398225.

Janssen, P., Berghe, P.V., Verschueren, S., Lehmann, A., Depoortere, I., and Tack, J. 2011. Review article: the role of gastric motility in the control of food intake. Aliment Pharmacol. Ther. 33(8): 880-894. doi:10.1111/j.1365-2036.2011. 04609.x. PMID:21342212.

Jentjens, R., and Jeukendrup, A.E. 2003. Determinants of post-exercise glycogen synthesis during short-term recovery. Sports Med. 33(2): 117-144. doi:10.2165/ 00007256-200333020-00004. PMID:12617691.

Kawaguchi, M., Scott, K.A., Moran, T.H., and Bi, S. 2005. Dorsomedial hypothalamic corticotropin-releasing factor mediation of exercise-induced anorexia. Am. J. Physiol. Regul. Integr. Comp. Physiol. 288(6): R1800-R1805. doi:10.1152/ ajpregu.00805.2004. PMID:15677523.

Kawano, H., Mineta, M., Asaka, M., Miyashita, M., Numao, S., Gando, Y., et al. 2013. Effects of different modes of exercise on appetite and appetiteregulating hormones. Appetite, 66: 26-33. doi:10.1016/j.appet.2013.01.017. PMID:23402716.

Kim, B.J., Carlson, O.D., Jang, H.J., Elahi, D., Berry, C., and Egan, J.M. 2005 Peptide YY is secreted after oral glucose administration in a gender-specific manner. J. Clin. Endocrinol. Metab. 90(12): 6665-6671. doi:10.1210/jc.20050409. PMID:16174724.

King, J.A., Wasse, L.K., Ewens, J., Crystallis, K., Emmanuel, J., Batterham, R.L., and Stensel, D.J. 2011. Differential acylated ghrelin, peptide YY3-36, appetite, and food intake responses to equivalent energy deficits created by exercise and food restriction. J. Clin. Endocrinol. Metab. 96: 1114-1121. doi:10.1210/jc. 2010-2735. PMID:21270331.

Martins, C., Stensvold, D., Finlayson, G., Holst, J., Wisloff, U., Kulseng, B., et al. 2015. Effect of Moderate- and High-Intensity Acute Exercise on Appetite in Obese Individuals. Med. Sci. Sports Exerc. 47(1): 40-48. PMID:24824772.

Mifflin, M.D., Jeor, S.T., Hill, L.A., Scott, B.J., Daugherty, S.A., and Koh, Y.O. 1990.
A new predictive equation for resting energy expenditure in healthy individuals. Am. J. Clin. Nutr. 51: 241-47. PMID:2305711.

Neary, M.T., and Batterham, R.L. 2009. Peptide YY: food for thought. Physiol. Behav. 97: 616-619. doi:10.1016/j.physbeh.2009.02.024. PMID:19268484.

Panissa, V.L.G., Alves, E.D., Salermo, G.P., Franchini, E., and Takito, M.Y. 2016. Can short-term high-intensity intermittent training reduce adiposity? Sport Sci. Health, 12(1): 99-104. doi:10.1007/s11332-016-0260-6.

Patterson, M., Bloom, S.R., and Gardiner, J.V. 2011. Ghrelin and appetite control in humans - Potential application in the treatment of obesity. Peptides, 32(11): 2290-2294. doi:10.1016/j.peptides.2011.07.021. PMID:21835215.

Schubert, M.M., Desbrow, B., Sabapathy, S., and Leveritt, M. 2013. Acute exercise and subsequent energy intake. A meta-analysis. Appetite, 63: 92-104. PMID: 23274127.

Schubert, M.M., Sabapathy, S., Leveritt, M., and Desbrow, B. 2014. Acute exercise and hormones related to appetite regulation: a meta-analysis. Sports Med. 44(3): 387-403. doi:10.1007/s40279-013-0120-3. PMID:24174308.

Sim, A.Y., Wallman, K.E., Fairchild, T.J., and Guelfi, K.J. 2014. High-intensity intermittent exercise attenuates ad-libitum energy intake. Int. J. Obes. 38(3): 417-422. doi:10.1038/ijo.2013.102. PMID:23835594.

Thorogood, A., Mottillo, S., Shimony, A., Filion, K.B., Joseph, L., Genes, J., et al. 2011. Isolated aerobic exercise and weight loss: a systematic review and metaanalysis of randomized controlled trials. Am. J. Med. 124(8): 747-755. doi:10. 1016/j.amjmed.2011.02.037. PMID:21787904.

Trapp, E.G., Chisholm, D.J., Freund, J., and Boutcher, S.H. 2008. Effects of highintensity intermittent exercise training on fat loss and baseline insulin concentrations of young women. Int. J. Obes. 32: 684-691. doi:10.1038/sj.ijo. 0803781. PMID:18197184.

Tucci, S.A., Murphy, L.E., Boyland, E.J., Dye, L., and Halford, J.C.G. 2010. Oral contraceptive effects on food choice during the follicular and luteal phases of the menstrual cycle. A laboratory based study. Appetite, 55(3): 388-392. PMID:20561549.

Woods, S.C. 2009. The control of food intake: behavioral versus molecular perspectives. Cell Metab. 9(6): 489-498. doi:10.1016/j.cmet.2009.04.007. PMID: 19490904. 